\title{
Evaluation of the ASK Campaign in Two Midwestern Cities
}

\author{
Renee M. Johnson, ${ }^{1,2}$ Jennie Lintz, ${ }^{3}$ Dan Gross, ${ }^{3}$ Matthew Miller, ${ }^{4}$ and David Hemenway ${ }^{2,4}$ \\ ${ }^{1}$ Department of Community Health Sciences, Boston University School of Public Health, Boston, MA 02118, USA \\ ${ }^{2}$ Harvard Youth Violence Prevention Center, Harvard School of Public Health, Boston, MA 02115, USA \\ ${ }^{3}$ The Center to Prevent Youth Violence, New York, NY, USA \\ ${ }^{4}$ Department of Health Policy and Management, Harvard School of Public Health, Boston, MA 02115, USA
}

Correspondence should be addressed to Renee M. Johnson, rjohnson@bu.edu

Received 16 August 2011; Accepted 20 September 2011

Academic Editor: A. Zaborskis

Copyright (C) 2012 Renee M. Johnson et al. This is an open access article distributed under the Creative Commons Attribution License, which permits unrestricted use, distribution, and reproduction in any medium, provided the original work is properly cited.

\begin{abstract}
We implemented a year-long community-based campaign to encourage parents to ask about firearms in homes that their children visit, in a small Midwestern city. Along with community residents and local leaders, we disseminated campaign messages through multiple communication channels. To assess message recall, attitudes, and whether parents asked about firearms, we conducted pre- and posttest surveys with randomly sampled adults in the intervention city and in a neighboring city. The posttest survey showed that parents in the intervention city were concerned about the danger of firearms when their child visits a friend's home, suggesting that the campaign influenced their attitudes.
\end{abstract}

\section{Introduction}

Firearm injuries are a major public health problem for children and youth in the United States [1-3]. Residential environments-including young people's own homes or the homes of relatives or friends - are leading settings for pediatric firearm injuries $[4,5]$ and are also the primary locations from which youth obtain firearms that are subsequently associated with an injury $[4,6-8]$. When youth are unintentionally killed with a firearm, they are most often shot by another young person [9]. Evidence indicates that safe storage of firearms can reduce the risk of child firearm injuries [10].

Many parents are aware that their children may be exposed to firearms in the homes of relatives and friends and are concerned about the risk of injury. A large, national study that asked parents about their attitudes toward having their children visit homes with firearms found that $31 \%$ of parents said they would not let their child play at or visit a home that contained a handgun - even if the gun were stored locked away and unloaded [11]. More than half of all parents would not allow their child to visit a home with a gun that was unlocked; $90 \%$ would forbid their child from visiting if the gun were loaded and unlocked.

One strategy for parents to find out whether guns are present in the homes where their children spend time is to talk to the adults in those homes. The Center to Prevent Youth Violence's (CPHV) "ASK" campaign teaches parents to do just that; ASK is an acronym for Asking Saves Kids. The aim of the national ASK campaign is to encourage parents to ask adults in whose homes their children spend time about the presence and storage of household firearms, with the long-term goal of reducing the rate of pediatric firearm injury.

In addition to the national campaign, CPHV implemented a health communication campaign promoting the ASK message in a Midwestern city, using a community-based prevention marketing approach [12]. Community-based prevention marketing incorporates community-organizing principles and marketing strategies in the design of community campaigns. The purpose of this study is to describe implementation of the local ASK campaign and to examine whether exposure to it was associated with changes in attitudes, knowledge, beliefs, and practices that are consistent with asking other adults about household firearms. 


\section{Methods}

2.1. Setting and Design. Comparing the intervention city to a control city, this evaluation employed an adaptation of the two-group before-after design [13]. It was modified in that the intervention — the local ASK campaign — was applied at a community (versus individual) level and in that participants to the pre- and posttest surveys were not the same people. There was no campaign in the control city.

By design, the intervention and control cities were similar to one another. They were in the same Midwestern state and were less than a 2-hour drive from a major city. Also, both had similar population sizes (greater than 100,000 people) and a median resident age of 32 years [14]. In both cities, one-fifth of the residents had a bachelor's degree and twothirds were White. Compared to the intervention city, the control city had a slightly larger percentage of Latinos and a higher median household income [14].

2.2. The ASK Campaign: Planning and Implementation. The ASK campaign in the intervention city took place from June 2005 through June 2007. As is consistent with the community-based prevention marketing model, the first year involved: (1) development of media messages; (2) endorsement from elected officials, community leaders, and other stakeholders; (3) creation of a local grassroots network of individuals and organizations to do advocacy work and conduct outreach; and (4) creation of campaign products, for example, brochures and billboards. The year-long planning phase afforded CPHV the time to garner buy-in, forge strong relationships, and create an outreach plan that was consistent with the city's interests. To design campaign messages, communication experts worked with community leaders to place an emphasis on humor rather than fear.

After a year of planning, it was decided that the core message of the campaign would be "ASK: Is there a gun where my child plays?" A secondary message highlighted how common firearms are, with the message that: "Over 5,000 children in our city live with guns." Implementation of the ASK campaign took place from June 2006-June 2007 and involved promoting the core and secondary messages in multiple settings and through a variety of communication channels.

City government, local institutions, and communitybased groups-including health clinics, schools, the police department, faith-based organizations, and businesses-participated in the campaign by hosting events, distributing materials, and integrating the ASK messages into their regular operations. ASK information booths were established at several community events. For example, the local police department distributed information about the ASK campaign as part of their "National Police Week" activities. Asking about firearms was promoted by featuring well-known figures in the city-including the mayor, leaders in law enforcement, and a sports mascot-in PSAs and outdoor advertisements with the proclamation "I ASK." Additionally, videos featuring a mother telling her personal story about losing her child to a firearm injury and the importance of asking about firearms were shown in medical waiting areas.
The city's autonomous media market allowed for an intensive, custom approach to message dissemination. CPHV produced high-quality, locally tailored public service messages that were broadcast citywide through several channels, including newspaper, mailings, billboards, signs on city buses, and radio. All media placement was donated by community groups, local government, or local businesses. In addition to planned messages, the campaign also received significant news coverage on television, radio, and in the newspaper.

2.3. Data Collection. Data come from telephone surveys of adults in the intervention and control cities. Precampaign survey administration took place from April 25-May 6, 2006, and post-campaign survey administration took place from June 22-July 11, 2007. The surveys were conducted by Marketing \& Research Resources, Inc., a social science research firm in Fredericksburg, Md, USA. Using a list-assisted random-digit-dialing sampling procedure [15], telephone numbers were randomly generated to include households with listed and unlisted numbers. Once a telephone number had been randomly selected for calling, as many as 10 callbacks were made.

Eligible respondents were 18-64-year-old residents of the intervention and control cities, who had children aged 5-14 years. Individuals who had participated in the pre-campaign survey were excluded from taking part in the post-campaign survey. Secondary analysis of survey data was approved by the Office of Human Research Administration at the Harvard School of Public Health.

The data collection instrument had 37 items and inquired about demographic characteristics; recall of "FILES," a fictional campaign; and recall of the ASK campaign. Near the beginning of the survey, respondents were asked two unaided questions about the ASK campaign ("Have you heard of the ASK Campaign?"), with an affirmative answer followed by an open-ended item that asked what the campaign was about. Near the end of the survey, respondents were asked an aided question ("Have you seen the message: ASK-Is there a gun where your child plays?"). The survey also inquired about: (1) the presence and storage of household firearms, (2) attitudes and beliefs regarding asking about firearms, or being asked by others about them, and (3) whether the respondents had ever asked-or been asked by othersabout firearms in the home. The survey was designed to be completed in 10 minutes.

We assessed whether respondents in the two cities could recall the ASK message both before and after the campaign, and also examined the extent to which their attitudes, beliefs, and behaviors were more likely to be consistent with the ASK message at the post-campaign survey, as compared to results from the pre-campaign survey. We expected to see that those in the intervention city would be more likely to recall ASK and would also be more likely to have favorable attitudes toward asking about the presence and storage of firearms. Within each city, the statistical significance of preversus post-campaign differences in knowledge, attitudes, and behavior was assessed by estimating prevalence ratios (PRs) with 95\% confidence intervals [16]. We also examined 
TABLE 1: Description of the study samples, before and after the ASK campaign, $n=1,600$.

\begin{tabular}{|c|c|c|c|c|}
\hline & \multicolumn{2}{|c|}{ Intervention city } & \multicolumn{2}{|c|}{ Control city } \\
\hline & Before & After & Before & After \\
\hline Female & $47 \%$ & $50 \%$ & $47 \%$ & $60 \%$ \\
\hline Attended or completed college & $83 \%$ & $86 \%$ & $78 \%$ & $74 \%$ \\
\hline White, non-Hispanic & $92 \%$ & $93 \%$ & $81 \%$ & $69 \%$ \\
\hline Age, y, M (SD) & $41.7(6)$ & $41.9(6)$ & $40.7(7)$ & $38.4(8)$ \\
\hline Married/cohabitating* & $94 \%$ & $93 \%$ & $88 \%$ & $84 \%$ \\
\hline Firearms in the home & $25 \%$ & $26 \%$ & $24 \%$ & $22 \%$ \\
\hline
\end{tabular}

Note. There were 400 respondents in each group. Within the control city, there were statistically significant differences in gender, educational attainment, race/ethnicity, age, and marital status in the pre- versus post-campaign samples $(P<0.05)$.

*Compared to people who are not married and who are not living with an intimate partner, that is, including those who are single, separated, divorced, or widowed.

whether respondents who had heard of the ASK campaign were more likely to have asked the adults in whose home their children play or visit about firearms. Analyses were conducted using SAS version 9.1.3 [17].

\section{Results}

3.1. Sample Description. In total, 1,600 residents were surveyed: 400 respondents each to the pre- and post-campaign surveys in the intervention city, and 400 respondents each to the pre- and post-campaign surveys in the control city. Of the 8,000 telephone numbers dialed for the pre-campaign survey, $10 \%$ resulted in a completed interview, 39\% were ineligible (e.g., no child aged 5-14 in the home), 18\% were refusals, and $33 \%$ were noncontacts (i.e., contact with a household member could not be made after 10 attempts). The vast majority of ineligible dispositions were cast because the telephone number was not in service or had been disconnected. The pattern of call dispositions was similar for the post-campaign survey. Of the 9,998 numbers dialed, $8 \%$ resulted in completed interviews, 59\% resulted in a disposition of ineligible, $12 \%$ were refusals, and $21 \%$ were non-contacts.

In the pre-campaign survey, the demographic composition of the intervention and control city samples were similar to one another and reflected the demographic composition of the cities as reported in the US census [14]. The majority of respondents were White, married, and had some postsecondary education. The prevalence of household firearm ownership was similar across the two cities (Table 1).

3.2. Campaign Recall. On the pre-campaign survey, less than $1 \%$ of respondents in each city said they had heard of "FILES," a fictional campaign. By contrast, 7\% of those in the intervention city and $6 \%$ in the control city said they had heard of the ASK campaign, though only one person out of 800 could identify that it had something to do with firearms (Table 2). After the campaign, the percentage of respondents who said they had heard of the ASK campaign was significantly higher in the intervention city than in the control city (15\% versus 5\%). Among those who had heard of the ASK campaign, $48 \%$ (28 out of 58 ) in the intervention city correctly indicated that it was about firearm safety, whereas just $11 \%$ ( 2 out of 19 ) in the control city did so. In other words, following implementation of the ASK campaign, $7 \%$ of those in the intervention city had heard of the ASK campaign and could identify that it was about firearms, compared to less than $1 \%$ of those in the intervention city.

At the end of the post-campaign survey, respondents were asked whether they had seen the message: "ASK: Is there a gun where your child plays?" (i.e., "aided recall"). Thirty percent of intervention city respondents responded affirmatively, compared to $6 \%$ of respondents in the control city (Table 2 ). All media components played a role in raising awareness of the ASK campaign. The most commonly mentioned media channel for recalled exposure to the ASK campaign was television public service announcements (42\%), followed by television news coverage (37\%), brochures (32\%), take-home materials from children's schools (32\%), and word of mouth (22\%). Radio and billboards advertisements were also mentioned by respondents.

3.3. Attitudes toward Asking about Firearms. At the precampaign survey, respondents in both cities had favorable attitudes toward asking about household firearms. About two-thirds of respondents in both cities thought it was a good idea to ask about the presence of a gun before leaving their child at someone else's home (Table 3). Women were significantly more likely than men to look favorably upon asking about household firearms. Prior to the campaign, $74 \%$ of women and $60 \%$ of men in the intervention city thought it was a good idea to ask about the presence of a gun $(P<0.05)$, as did $79 \%$ of women and $61 \%$ of men in the control city $(P<0.05)$. Approximately three-fourths $(72 \%)$ of respondents in the intervention city and $70 \%$ in the control city said that in the future they were likely to ask about firearms in homes where their children play or visit; women were significantly more likely than men to say they would ask. Despite favorable attitudes, a minority of respondents reported ever having asked about firearm safety, either before or after the campaign (i.e., $33 \%$ in the intervention city and $26 \%$ in the control city). Only about one in ten in both cities indicated that they had ever been asked about firearms in their own homes.

Comparing pre- to post-campaign survey results within each city, there were no statistically significant differences in 
TABLE 2: Reported exposure to the ASK campaign.

\begin{tabular}{lcccc}
\hline & \multicolumn{2}{c}{ Pre-campaign survey } & \multicolumn{2}{c}{ Post-campaign survey } \\
& $\begin{array}{c}\text { Intervention city } \\
(400)\end{array}$ & $\begin{array}{c}\text { Control city } \\
(400)\end{array}$ & $\begin{array}{c}\text { Intervention city } \\
(400)\end{array}$ & Control city (400) \\
\hline $\begin{array}{l}\text { Unaided recall of FILES, a fictional } \\
\text { campaign }\end{array}$ & $<1 \%(3)$ & $<1 \%(2)$ & $<1 \%(3)$ & $15 \%(58)$ \\
$\begin{array}{l}\text { Unaided recall of the ASK campaign } \\
\text { Indicated that ASK campaign related }\end{array}$ & $7 \%(27)$ & $6 \%(24)$ & $7 \%(28)$ & $5 \%(19)$ \\
to firearm safety & $0 \%(0)$ & & $30 \%(118)$ & $61 \%(2)$ \\
Aided recall of the ASK Campaign & & & $6 \%(24)$ \\
\hline
\end{tabular}

TABLE 3: Beliefs, behavior, and intentions of a sample of Midwesterners before and after implementation of the ASK campaign, $n=1,600$.

\begin{tabular}{|c|c|c|c|c|}
\hline \multirow{2}{*}{ Percentage... } & \multicolumn{2}{|c|}{ Intervention city } & \multicolumn{2}{|c|}{ Control city } \\
\hline & $\begin{array}{l}\text { Pre- versus } \\
\text { post-campaign Survey }\end{array}$ & Adjusted PR (95\% CI) & $\begin{array}{c}\text { Pre- versus } \\
\text { post-campaign Survey }\end{array}$ & Adjusted PR (95\% CI) \\
\hline $\begin{array}{l}\text { Who believe it is good idea to ask } \\
\text { about household firearms before } \\
\text { leaving child at someone else's } \\
\text { home }\end{array}$ & $66 \%$ versus $71 \%$ & $1.06(0.96,1.17)$ & $65 \%$ versus $70 \%$ & $1.00(0.92,1.11)$ \\
\hline $\begin{array}{l}\text { Who say they are likely to ask } \\
\text { about household firearms in the } \\
\text { future }\end{array}$ & $72 \%$ versus $75 \%$ & $0.91(0.72,1.15)$ & $70 \%$ versus $69 \%$ & $1.08(0.86,1.35)$ \\
\hline $\begin{array}{l}\text { Who have ever asked about } \\
\text { firearms in homes their children } \\
\text { visit }\end{array}$ & $33 \%$ versus $31 \%$ & $0.88(0.71,1.08)$ & $26 \%$ versus $31 \%$ & $1.09(0.86,1.37)$ \\
\hline $\begin{array}{l}\text { Who have ever been asked about } \\
\text { firearms in their own homes }\end{array}$ & $11 \%$ versus $11 \%$ & $0.99(0.66,1.50)$ & $10 \%$ versus $11 \%$ & $0.98(0.64,1.50)$ \\
\hline $\begin{array}{l}\text { Who are concerned about the } \\
\text { danger of firearms when their } \\
\text { children visit a friend or } \\
\text { neighbor's home }\end{array}$ & $38 \%$ versus $46 \%$ & $1.18(1.00,1.41)$ & $48 \%$ versus $56 \%$ & $1.08(0.93,1.24)$ \\
\hline
\end{tabular}

Note. PR: prevalence ratio, CI: confidence interval. All models are adjusted for sex, marital status (married versus not married), age, race/ethnicity (White, non-Hispanic versus all else), and educational attainment (high school or less versus any postsecondary education).

attitudes toward asking, except that in the intervention city, respondents to the post-campaign survey were more likely to be concerned about the danger of firearms in homes their children visit (Adj. PR = 1.18, 95\% CI: 1.00, 1.41) (Table 3). Concern about household firearms increased significantly among non-Hispanic Whites. At the pre-campaign survey, $36 \%$ were concerned about household firearms, whereas $46 \%$ were at the post-campaign survey $(\mathrm{PR}=1.29,95 \%$ CI: $1.08,1.54)$ (not shown). A similar increase in concern about firearms in the control city post-campaign sample was largely explained by that sample's disproportionately high percentage of women. Women were more likely than men to be concerned about firearms, and the control city sample had $47 \%$ women in the pre-campaign and $60 \%$ women in the post-campaign.

Respondents were asked whether they would feel uncomfortable if a parent asked them about household firearms and were also asked to estimate the percentage of parents who, they thought, would be offended if they were asked about firearms. Only $13 \%$ of respondents said that they would be offended if another parent asked them about firearms. By contrast, the median estimate of the percentage of other parents who would be offended if asked about firearms was $25 \%$. These percentages were not significantly different by city or over time (pre- versus post-campaign). Interestingly, there was no statistically significant difference in responses to either of these questions between respondents with versus without firearms in the home.

Attitudes, beliefs, and behaviors among intervention city respondents to the post-campaign survey varied based on whether they reported that they had heard of the ASK campaign. Those who responded yes to the aided recall question (i.e., "Have you seen or heard the message: Ask, is there a gun where your child plays?") were significantly more likely both to be concerned about the danger of firearms when their child visits another home ( $56 \%$ versus $42 \%, P<0.05)$ and to have ever asked about firearm safety in homes where their children play or visit ( $40 \%$ versus $26 \%, P<0.01$ ) (Table 4 ). They were also slightly more likely to say they would ask about firearm safety in the future $(81 \%$ versus $72 \%, P=$ $0.08)$. Eighty-three percent of those who recalled the campaign when asked the unaided question (i.e., Have you ever heard of the ASK Campaign?") $(n=58)$ believed that it was a good idea to ask about firearms. 
TABLE 4: Attitudes, beliefs, and practices following the ASK campaign, by campaign recall (post-campaign, intervention city), $n=400$.

\begin{tabular}{|c|c|c|}
\hline \multirow[t]{2}{*}{ Percentage... } & \multicolumn{2}{|c|}{$\begin{array}{l}\text { Have you seen or heard the message: ASK-Is } \\
\text { there a gun where your child plays? }\end{array}$} \\
\hline & Yes $(n=118)$ & No $(n=270)$ \\
\hline $\begin{array}{l}\text { Who feel it is a good idea to ask whether there is a gun present before their child } \\
\text { spends time in someone else's home }\end{array}$ & $74 \%$ & $69 \%$ \\
\hline $\begin{array}{l}\text { Who are concerned about the danger of firearms when their child visits a friend or } \\
\text { neighbor's home }\end{array}$ & $56 \% *$ & $42 \%$ \\
\hline Who have ever asked about guns in homes their children visit & $40 \% *$ & $26 \%$ \\
\hline $\begin{array}{l}\text { Who, if they knew a gun was present in a home their children visit, would either } \\
\text { confirm that it was stored safely or would not let their children visit the home }\end{array}$ & $92 \%$ & $88 \%$ \\
\hline Who would feel uncomfortable if a parent asked them about guns in their home & $9 \%$ & $13 \%$ \\
\hline Who believe that most parents would not mind being asked about guns in the home & $53 \%$ & $53 \%$ \\
\hline Who say they are likely to ask about a gun in the home in the future & $81 \%$ & $72 \%$ \\
\hline
\end{tabular}

Note. Analyses are restricted post-campaign survey results from residents of the intervention city.

* The difference in proportions from the pre- to post-campaign survey was statistically significant at $P<0.05$.

\section{Discussion}

The Center for Prevent Youth Violence (formerly known as PAX) conducted a year-long comprehensive, communitybased campaign in a small Midwestern city promoting the importance of parents asking adults in whose homes their children play or visit about household firearms and their safe storage. Residents of the intervention city were significantly more likely to recall the campaign as compared to residents of a similar city that had not received the campaign. Thirty percent of the intervention city respondents said they had heard about the ASK campaign, whereas just $6 \%$ of control city respondents had.

Respondents' attitudes and behavioral intentions changed modestly, but not significantly, in the expected direction in the intervention city. Unfortunately, the sample size was too small to detect even large changes. For example, $66 \%$ of the parents already thought it was a good idea to ask about firearms before leaving their child at someone else's home. Getting $20 \%$ of the remainder to change their opinion (i.e., going from $66 \%$ to $73 \%$ ) would not have been enough of a change to reject the null hypothesis.

Before-after comparisons provide at most only very modest evidence that the campaign may have resulted in changes in either beliefs or actions. Changes in responses to the one question that reached statistical significance were whether the parent was concerned about the danger of firearms when their children visit a friend's or neighbor's home. Post-campaign results suggest this was probably due to changes among those respondents who had seen or heard the ASK message. Generally, at the post-campaign survey, intervention residents who reported having heard of the campaign were more favorably disposed to its message than those who had not heard the campaign. These results suggest that the campaign may have had the intended effect. Alternatively, these results could indicate that the message effectively reached, or was remembered by, those predisposed to agree with the message.

Results from both cities show that most parents think that asking about firearms is a good idea and that few would feel uncomfortable if another parent asked them about firearms in their home. However, their perceptions about other parents' attitudes do not appear to correspond to this reality. Fifty-one percent of the 1,600 responding parents estimate that more than one-fourth of parents would mind being asked about guns in the home. Yet, only 13\% would feel uncomfortable about being asked. These results indicate that parents overestimate the likelihood that asking about firearms is offensive to others.

There are several limitations to this research. This study is limited in generalizability because it only covers two small cities in the Midwest and only evaluates short-term effects of the campaign. As with most survey research, there may be inaccurate reporting due to many factors including recall bias or the tendency to provide socially desirable responses. There seems to be evidence of some social desirability reporting. For example, approximately one-third of the 1,600 respondents claim to have asked about firearms in the homes their children visit, but only $11 \%$ report ever having been asked. It is virtually impossible to reconcile these estimates. The strengths of the evaluation include a control group and before-after surveys conducted by an independent firm. The results are encouraging because many parents already report believing that asking about guns and gun storage is important and acceptable.

Because of the dangers of firearms, public health and medical professionals conduct anticipatory guidance with parents, encouraging them to ask about firearm safety in the homes in which their children play or visit [18]. Our findings suggest that most parents will be comfortable with this type of conversation. This is particularly true for those parents who report having heard of the ASK campaign.

\section{References}

[1] G. B. Eber, J. L. Annest, J. A. Mercy, and G. W. Ryan, "Nonfatal and fatal firearm-related injuries among children aged 14 years and younger: United States, 1993-2000," Pediatrics, vol. 113, no. 6, pp. 1686-1692, 2004. 
[2] L. A. Fingerhut and K. K. Christoffel, "Firearm-related death and injury among children and adolescents," Future of Children, vol. 12, no. 2, pp. 25-37, 2002.

[3] E. C. Powell, E. Jovtis, and R. R. Tanz, "Incidence and circumstances of nonfatal firearm-related injuries among children and adolescents," Archives of Pediatrics and Adolescent Medicine, vol. 155, no. 12, pp. 1364-1368, 2001.

[4] D. C. Grossman, D. T. Reay, and S. A. Baker, "Self-inflicted and unintentional firearm injuries among children and adolescents: the source of the firearm," Archives of Pediatrics and Adolescent Medicine, vol. 153, no. 8, pp. 875-878, 1999.

[5] J. R. Martin, D. P. Sklar, and P. McFeeley, "Accidental firearm fatalities among New Mexico children," Annals of Emergency Medicine, vol. 20, no. 1, pp. 58-61, 1991.

[6] C. M. Callahan and F. P. Rivara, "Urban high school youth and handguns: a school-based survey," JAMA, vol. 267, no. 22, pp. 3038-3042, 1992.

[7] Centers for Disease Control and Prevention, "Source of firearms used by students in school-associated violent deathsUnited States, 1992-1999," Morbidity \& Mortality Weekly Report, vol. 52, no. 09, pp. 169-172, 2003.

[8] R. M. Johnson, C. Barber, D. Azrael, D. E. Clark, and D. Hemenway, "Who are the owners of firearms used in adolescent suicides?" Suicide and Life-Threatening Behavior, vol. 40, no. 6, pp. 609-611, 2010.

[9] D. Hemenway, C. Barber, and M. Miller, "Unintentional firearm deaths: a comparison of other-inflicted and self-inflicted shootings," Accident Analysis and Prevention, vol. 42, no. 4, pp. 1184-1188, 2010.

[10] D. C. Grossman, B. A. Mueller, C. Riedy et al., "Gun storage practices and risk of youth suicide and unintentional firearm injuries," JAMA, vol. 293, no. 6, pp. 707-714, 2005.

[11] T. W. Smith, 1997-98 National Gun Policy Survey of the National Opinion Research Center: Research Findings, National Opinion Research Center, University of Chicago, Chicago, Ill, USA, 1998.

[12] C. A. Bryant, K. R. Brown, R. J. McDermott et al., "Community-based prevention marketing: organizing a community for health behavior intervention," Health Promotion Practice, vol. 8, no. 2, pp. 154-163, 2007.

[13] T. D. Campbell and J. C. Stanley, Experimental and QuasiExperimental Designs for Research, Houghton-Mifflin Company, Boston, Mass, USA, 1967.

[14] U. S. Census Bureau. State and County Quick Facts, U. S. Department of Commerce, Economics and Statistics Administration (producer), 2008, http:/quickfacts.census.gov/qfd/ states/17000.html.

[15] J. Waksberg, "Sampling methods for random digit dialing," JAMA, vol. 73, pp. 40-46, 1978.

[16] D. Spiegelman and E. Hertzmark, "Easy SAS calculations for risk or prevalence ratios and differences," American Journal of Epidemiology, vol. 162, no. 3, pp. 199-200, 2005.

[17] SAS Version 9.1.3. Cary, NC: SAS Institute, 2007.

[18] K. S. McGee, T. Coyne-Beasley, and R. M. Johnson, "Review of evaluations of educational approaches to promote safe storage of firearms," Injury Prevention, vol. 9, no. 2, pp. 108-111, 2003. 


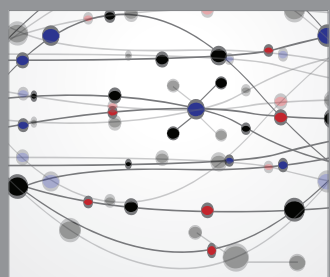

The Scientific World Journal
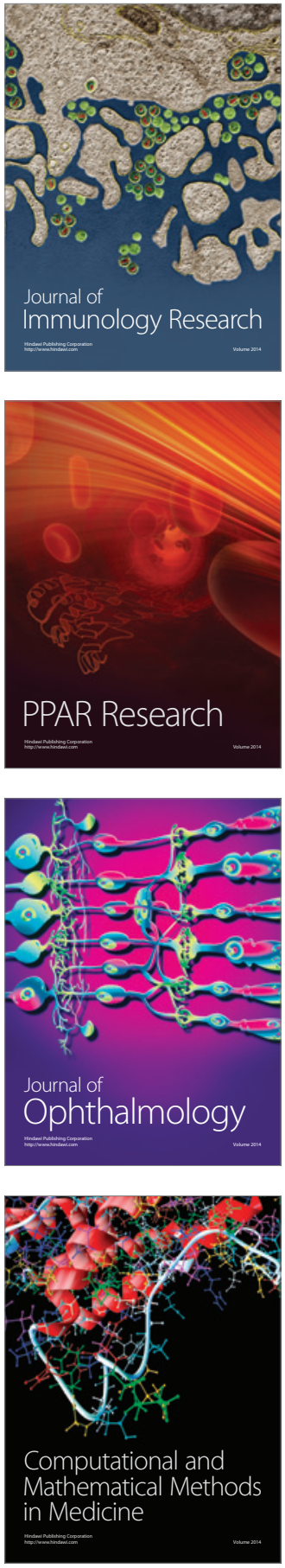

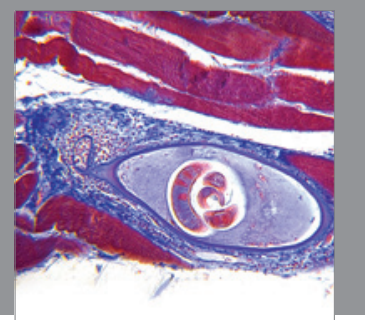

Gastroenterology

Research and Practice
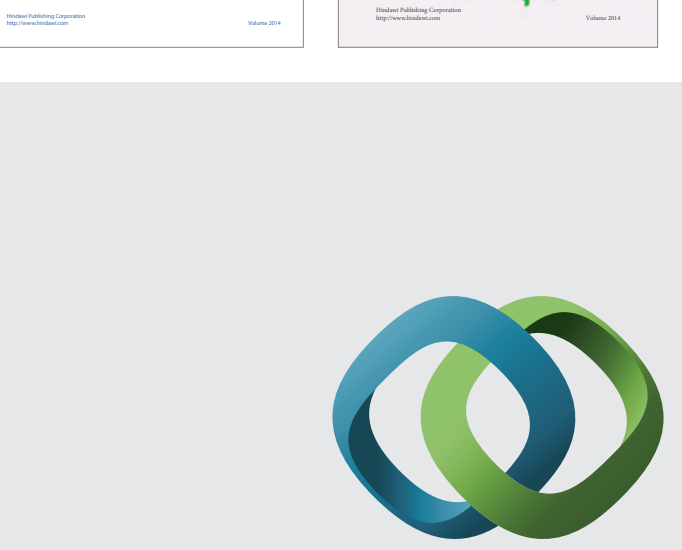

\section{Hindawi}

Submit your manuscripts at

http://www.hindawi.com
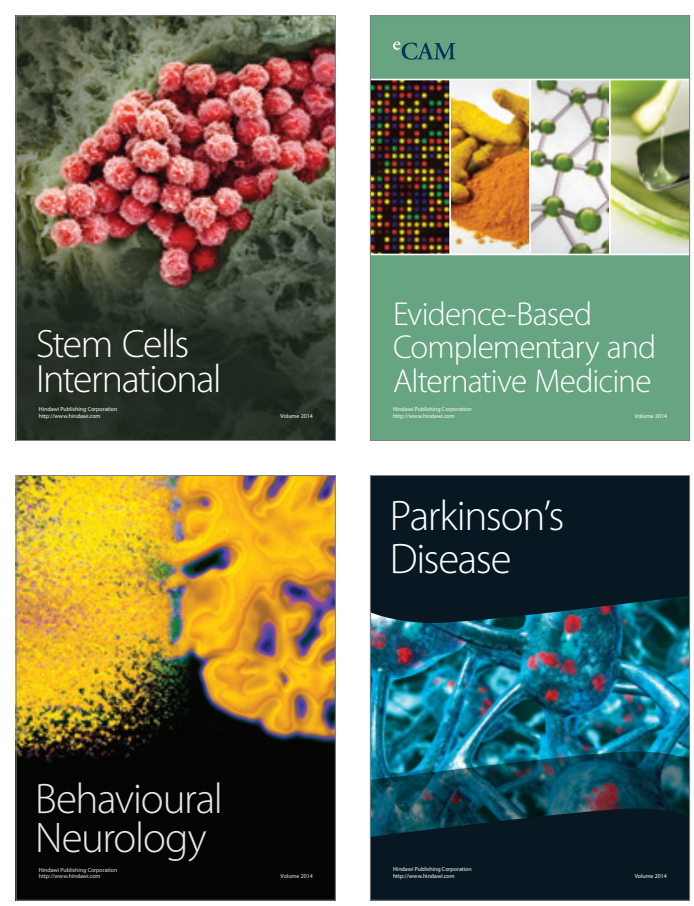

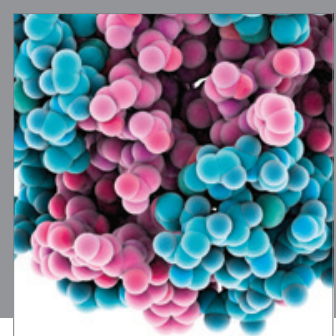

Journal of
Diabetes Research

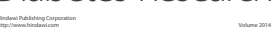

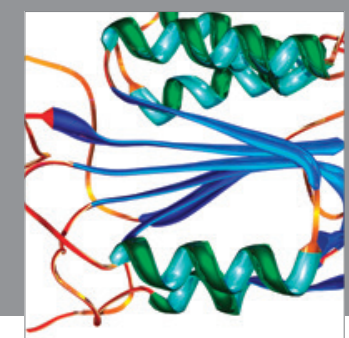

Disease Markers
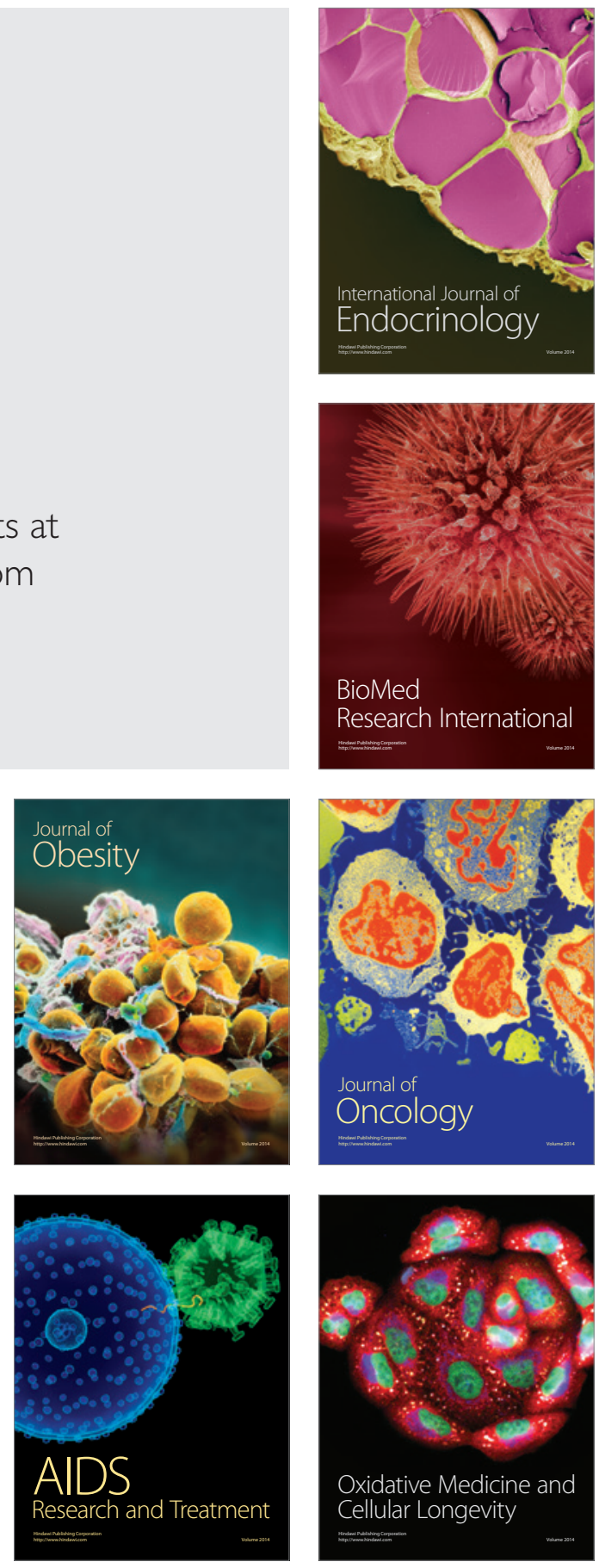